\title{
Internal-Notched Flexure Test for Measurement of Mode II Delamination Resistance of Fibre-Reinforced Polymers
}

\author{
Chengye Fan, ${ }^{1}$ P.-Y. Ben Jar, ${ }^{1}$ and J.-J. Roger Cheng ${ }^{2}$ \\ ${ }^{1}$ Department of Mechanical Engineering, University of Alberta, Edmonton, AB, Canada T6G 2G8 \\ ${ }^{2}$ Department of Civil \& Environmental Engineering, University of Alberta, Edmonton, AB, Canada T6G 2G7
}

Correspondence should be addressed to P.-Y. Ben Jar; ben.jar@ualberta.ca

Received 8 July 2013; Accepted 21 November 2013

Academic Editor: Baozhong Sun

Copyright (c) 2013 Chengye Fan et al. This is an open access article distributed under the Creative Commons Attribution License, which permits unrestricted use, distribution, and reproduction in any medium, provided the original work is properly cited.

\begin{abstract}
This paper introduces a new test, method, named internal-notched flexure (INF) test, that is designed to measure the critical energy release rate of fibre-reinforced polymers for delamination growth in shear mode (mode II). The INF test generates stable delamination growth, with a monotonic increase of load and displacement in a nearly linear fashion. Values of the mode II delamination toughness were deduced using experimental compliance fitting method. Good repeatability of the results was obtained. Compared with the end-notched flexure (ENF) test using the same material, the INF test yielded higher delamination resistance, possibly due to the bridging fibres found between fracture surfaces of the INF test specimens.
\end{abstract}

\section{Introduction}

The use of a starting defect to quantify materials fracture resistance was firstly used in Griffith's approach [1] for the measurement of the energy required to form fracture surfaces. The concept has since been adopted in many test methods to characterize toughness of a variety of materials. For fibre-reinforced polymers (FRP), this concept has successfully led to the development of double-cantilever beam (DCB) test that is now a standard method for measuring FRP's resistance to delamination in an opening mode (mode I). Many similar approaches have been attempted to develop a standard for the measurement of FRP's resistance to delamination in an in-plane shear mode (mode II), but with less success. Among the methods proposed, end-notched flexure (ENF) test [2], stabilized end-notched flexure (SENF) test [3], end-loaded split (ELS) test [4], and 4-point endnotched flexure (4ENF) test [5] are the most promising candidates for the standard, and rigorous efforts have been made to derive the corresponding expressions of energy release rate for delamination growth. Using simple beam theory, with the assumption of stress-free fracture surfaces, the expressions of critical energy release rate $\left(G_{\text {IIC }}\right)$ and beam flexure compliance $(C)$ are as follows.
For the ENF and SENF tests [2]

$$
G_{\mathrm{IIC}}^{\mathrm{ENF}}=\frac{9 P^{2} a^{2}}{16 w^{2} E_{1} h^{3}}, \quad C^{\mathrm{ENF}}=\frac{2 L^{3}+3 a^{3}}{8 E_{1} w h^{3}}
$$

for the ELS test [4]

$$
G_{\text {IIC }}^{\mathrm{ELS}}=\frac{9 P^{2} a^{2}}{4 w^{2} E_{1} h^{3}}, \quad C^{\mathrm{ELS}}=\frac{L^{3}+6 a^{3}}{8 E_{1} w h^{3}} ;
$$

for the 4ENF test [5]

$$
G_{\mathrm{IIC}}^{4 \mathrm{ENF}}=\frac{9 P^{2}(L-d / 2)^{2}}{16 w^{2} E_{1} h^{3}}, \quad C^{4 \mathrm{ENF}}=\frac{L^{3}}{32 E_{1} w h^{3}}\left(1+\frac{9 a}{L}\right),
$$

where $P$ is the critical load for the delamination growth, $w$ specimen width, $h$ half specimen thickness, $L$ half span length, $E_{1}$ flexure modulus, and $d$ in the expression for $G_{\mathrm{IIC}}^{4 \mathrm{ENF}}$ the distance between the two central loading pins.

With the assumption of constant $G_{\text {IIC }}$ during the delamination growth, the schematic load-displacement curves generated by the 4 delamination tests are presented in Figure 1 in which the delamination growth commences where the initial 


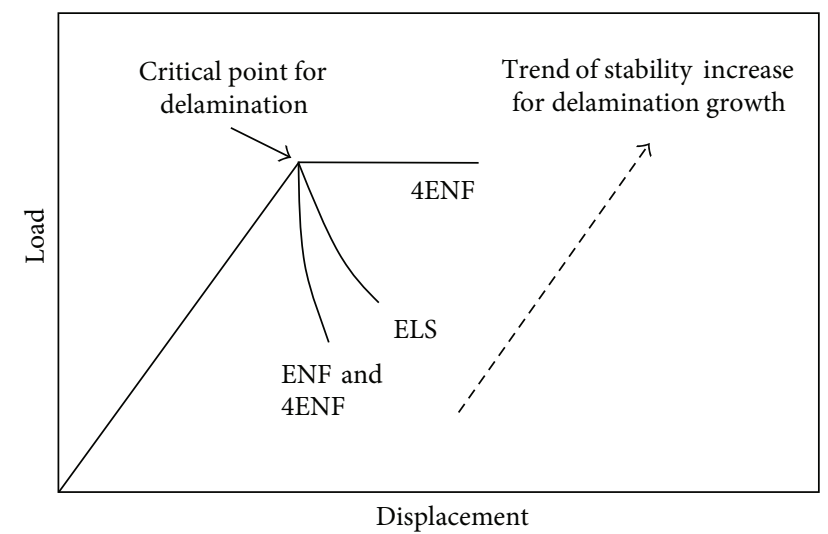

FIGURE 1: Schematic diagram of load-displacement curves from the existing mode II delamination tests.

slope of the loading curve is reduced. In principle, all tests are capable of generating stable delamination growth under displacement-controlled loading. For the ENF test, however, most test setups chose $1 / 2$ as the ratio for the initial crack length $a_{o}$ to the half span length $L$, in order to avoid extensive deflection for the delamination initiation. This has the tradeoff of causing unstable delamination growth. Therefore, the ENF test has not been used to establish a resistance curve for delamination ( $R$-curve) from a single test, which has been a major issue for the test to be a standard for delamination resistance characterization [6].

For the purpose of generating stable crack growth, SENF test adopts a feedback system to control the crack shear displacement (CSD) between the top and the bottom halves of the specimen at the cracked end. Although the SENF test can generate an $R$-curve using a single specimen, it requires some elaborate equipment and a tedious process to measure $\operatorname{CSD}[4,6]$.

The ELS test generates much more stable delamination growth than does the ENF test and thus can establish the $R$-curve from a single specimen. However, some loaddisplacement curves reported in the literature [7] show local zigzag oscillation of the loading that raises concerns about the true nature of the delamination growth. In addition, difficulties associated with clamping and the requirement of a relatively delicate apparatus to maintain the specimen in a horizontal position have reduced the interests in selecting the test as a standard [6].

At the point when this paper is prepared, the $4 \mathrm{ENF}$ test is the most promising candidate for the standard. The 4ENF test can generate stable delamination growth, though "stick-slip" crack growth does occur occasionally [5], indicating that the delamination growth is not always stable.

Overall, the major challenge faced in the course of designing a standard mode II delamination test is the capability of generating stable delamination growth in order to establish the $R$-curve that is an important piece of information for the evaluation of FRP's delamination resistance. An interesting trend indicated in Figure 1 is the stability of delamination growth that increases in the order of ENF/SENF, ELS, and

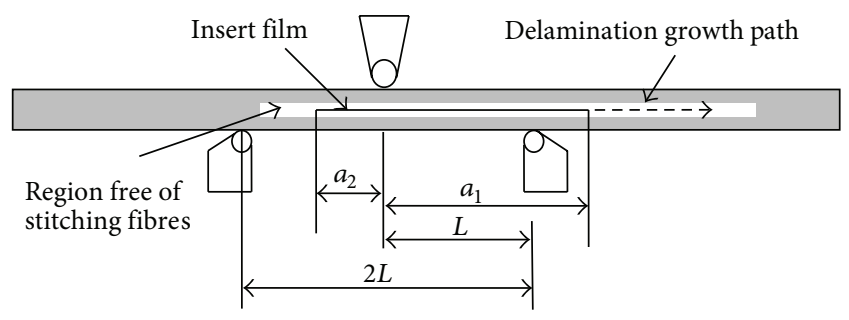

Figure 2: INF test setup.

4ENF. That is, the rate of load drop after the critical point of delamination serves as an indicator of the delamination growth stability.

This paper presents a new test method for the measurement of delamination resistance, which, unlike the curves in Figure 1, does not generate any load drop in the load-displacement curve after the delamination is initiated. Therefore, delamination growth is very stable. This paper will provide details of the new test method, its analytical validation, and some experimental results for demonstration using glass-fibre-reinforced polyester.

\section{The Proposed Mode II Delamination Test and Its Analysis}

The setup of the new delamination test is shown in Figure 2. The test applies 3-point bending to a beam specimen that has an insert film embedded in the midthickness, thus named internal-notched flexure (INF) test, similar to the setup of central-notched flexure (CNF) test [8]. The main difference between the two tests is the placement of the specimen in the 3-point bend device. Both tests use symmetrical 3-point loading, but the CNF test applies the load in the middle of the insert film with the span length longer than the insert film. The INF test, on the other hand, applies the load asymmetrically with respect to the insert film, with one end of the insert film being much closer to the loading pin than the other end, at a distance of $a_{2}$ and $a_{1}$, respectively, as shown in Figure 2. Also shown in Figure 2 is that $a_{1}$ is slightly longer than the half span length $L$. This is to ensure that compression from the loading or the supporting pins only acts on the starting film surfaces where the coefficient of friction should be very low, as the insert aluminium film is waxed prior to the fibre lay-up. This setup arrangement is expected to minimize the effect of friction on the measured delamination resistance.

Delamination growth in the INF test is expected to be in the direction of $a_{1}$, that is, in the overhanging section outside the span length, in which the specimen is free from any transverse loading. This, however, requires the INF specimen to have a sufficiently long overhanging section to provide the space for the delamination growth.

The INF test applies load under the displacement control, and records load, displacement, and the change of $a_{1}$ during the delamination growth. At the critical load for the delamination initiation, the slope of the loading curve drops, but the load still shows a relatively linear increase with the increase of the displacement, as schematically presented in Figure 3. 


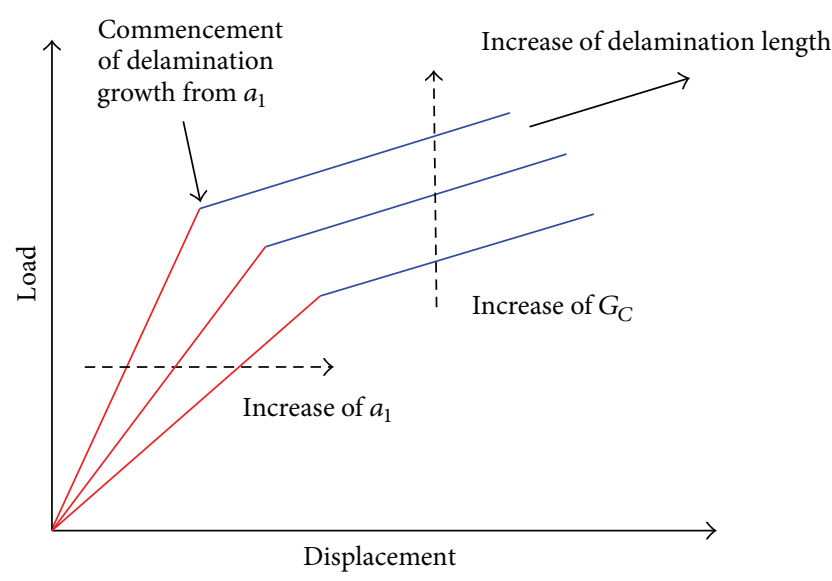

FIGURE 3: Schematic presentation of load-displacement curves from the INF tests, with variation in $a_{1}$ and $G_{C}$ values.

The load-displacement curve is expected to be bilinear, with the transition point occurring where the delamination is initiated.

2.1. Energy Release Rate $(G)$ and Delamination Mode. The embedded starting defect in the INF specimen provides two directions for the delamination growth. In the previous work [9] on the analysis of the delamination growth from an internal defect, we have derived an expression for compliance $C$ (the ratio of the displacement $\delta$ to the applied force $P$ ) that is applicable to the INF test. With the setup shown in Figure 2, the expression for $C$ is

$$
\begin{aligned}
C=\frac{\delta}{P} & \\
= & \frac{L^{3}}{4 w h^{3} E}+3\left[-3 L^{4}+4 a_{1} L^{3}+8 a_{2} L^{3}+6 a_{2}^{2} L^{2}+12 a_{1} a_{2} L^{2}\right. \\
& \left.\quad-12 a_{1} a_{2}^{2} L+4 a_{1} a_{2}^{3}+a_{2}^{4}\right] \\
& \times\left(32 E_{1} w h^{3}\left(a_{1}+a_{2}\right)\right)^{-1} .
\end{aligned}
$$

Based on the definition of the energy release rate $G$ for beam specimens

$$
G=\frac{P^{2}}{2 w} \frac{\partial C}{\partial a_{i}}
$$

the $G$ expressions for delamination growth in the two directions are

$$
\begin{gathered}
G_{a 1}=\frac{9 P^{2}}{64 E w^{2} h^{3}\left(a_{1}+a_{2}\right)^{2}}\left(a_{2}^{2}-2 a_{2} L-L^{2}\right)^{2}, \\
G_{a 2}=\frac{9 P^{2}}{64 E w^{2} h^{3}\left(a_{1}+a_{2}\right)^{2}}\left(a_{2}^{2}+L^{2}-2 a_{1} L+2 a_{1} a_{2}\right)^{2} .
\end{gathered}
$$

In order to ensure that the delamination growth is always in the $a_{1}$ direction, that is, from the right end of the insert film in Figure 2, value of $G_{a 1}$ has to be greater than $G_{a 2}$, which requires the following condition to be met [9]:

$$
L \leq a_{1} \leq \frac{L+a_{2}}{L-a_{2}} L .
$$

The above condition allows the delamination growth in the $a_{1}$ direction for a length of $\left(\left(\left(L+a_{2}\right) /\left(L-a_{2}\right)\right) L-a_{1}\right)$ before the delamination growth in the $a_{2}$ direction becomes favourable. An example of the choice of $a_{1}$ and $a_{2}$ will be given in Experimental Details, under the heading Delamination Test Setup and Procedure.

Equations (6) and (7) can also be derived using the approach of crack tip element (CTE) that was initially proposed by Davidson et al. [10] and Yang et al. [11]. Following the analysis given in [10] for a 2-dimensional orthotropic beam, the energy release rate $G$ for crack growth from an internal defect in $a_{i}$ direction is

$$
G_{a i}=\frac{\left(2 F_{C i}\right)^{2}}{E_{1} h}+\frac{3\left(2 M_{C i}\right)^{2}}{E_{1} h^{3}}, \quad i=1,2,
$$

where, for the INF specimen in Figure 2, the concentrated forces, $F_{C 1}$ and $F_{C 2}$, and the moments, $M_{C 1}$ and $M_{C 2}$, are

$$
\begin{gathered}
F_{C 1}=\frac{3 P}{16 w h\left(a_{1}+a_{2}\right)}\left(a_{2}^{2}-2 a_{2} L-L^{2}\right), \\
F_{C 2}=\frac{3 P}{16 w h\left(a_{1}+a_{2}\right)}\left(a_{2}^{2}+L^{2}-2 a_{1} L+2 a_{1} a_{2}\right), \\
M_{C 1}=M_{C 2}=0 .
\end{gathered}
$$

By substituting (10) to (9), same expressions as (6) and (7) are obtained.

In addition to the derivation of the energy release rate, the CTE analysis can also determine the mode mixing ratio for the delamination growth in the INF specimen. Equation (10) indicates that the delamination crack in the INF specimen is subject to concentrated forces $F_{i}$ only, with no involvement of any moment, which is the same condition as that for $4 \mathrm{ENF}$ specimens of the same fibre lay-up [4]. Therefore, the fracture mode introduced in the INF test should be the same as that in the 4ENF test, and, according to the analysis in [10], the two tests should be subject to a pure shear mode of fracture.

2.2. Stability of Delamination Growth. Stability of delamination growth is determined by $d G / d a$, of which negative value indicates stable delamination growth and positive unstable. The total energy release rate $G$ of the INF specimen is expressed in terms of $G_{a 1}$ and $G_{a 2}$, multiplied by a weighting factor that is equal to the fraction of the delamination length increase in that direction; that is,

$$
G=\frac{d a_{1}}{d a_{1}+d a_{2}} G_{a 1}+\frac{d a_{2}}{d a_{1}+d a_{2}} G_{a 2} .
$$

As mentioned earlier, an appropriate choice of initial $a_{1}$ and $a_{2}$ values to satisfy (8) will allow the delamination growth only in the $a_{1}$ direction for a certain distance within which $G$ 
is equivalent to $G_{a 1}$, with negative value of $d G_{a 1} / d a_{1}$ in both load- and displacement-controlled conditions. As a result, the INF test is expected to be able to generate stable delamination growth in both conditions.

2.3. Load-Displacement Curve and Delamination Growth Rate. The applied load $P$ and the corresponding displacement $\delta$ of the INF test can be expressed analytically as a function of critical strain energy release rate $G_{C}$. The expression for $P$ is simply through the rearrangement of (6) with $G_{C}$ replacing $G_{a 1}$ :

$$
P=\frac{8\left(a_{1}+a_{2}\right) \sqrt{E_{1} h^{3} w^{2} G_{C}}}{3\left(L^{2}+2 L a_{2}-a_{2}^{2}\right)} .
$$

The expression for the displacement $\delta$ is obtained by converting the above expression using (4):

$$
\begin{gathered}
\delta=\sqrt{G_{C}}\left(20 L^{3} a_{1}+36 a_{2} L^{2} a_{1}-36 L a_{2}^{2} a_{1}+12 a_{2}^{3} a_{1}\right. \\
\left.-16 a_{2} L^{3}-9 L^{4}+18 a_{2}^{2} L^{2}+3 a_{2}^{4}\right) \\
\times\left(12\left(L^{2}+2 L a_{2}-a_{2}^{2}\right) \sqrt{E_{1} h^{3}}\right)^{-1} .
\end{gathered}
$$

These expressions suggest that both $P$ and $\delta$ are linear functions of $a_{1}$.

Using (4) for the relationship between $P$ and $\delta$ before the onset of delamination and (12) and (13) after, the trend of change for the load-displacement curve from the INF test with respect to the increase of $a_{1}$ and $G_{C}$ is schematically illustrated in Figure 3. It should be noted that the curves in the figure are constructed based on the assumption of stressfree fracture surfaces that do not impose any barrier for the delamination growth. With this assumption, according to (12) and (13), the slope of the $P-\delta$ curve during the delamination growth should be independent of the $G_{C}$ value.

Since $\delta$ is a linear function of $a_{1}$, with $a_{2}$ and $G_{C}$ being constant, time derivative of (13) suggests that delamination growth rate $\dot{a}$ is a linear function of the test crosshead speed $\dot{\delta}$; that is,

$$
\dot{a}_{1}=\frac{12\left(L^{2}+2 L a_{2}-a_{2}^{2}\right) \sqrt{E h^{3}}}{\sqrt{G_{C}}\left(20 L^{3}+36 a_{2} L^{2}-36 L a_{2}^{2}+12 a_{2}^{3}\right)} \dot{\delta} .
$$

Therefore, by controlling the crosshead speed $\dot{\delta}$, the INF test can be used to reveal the effect of crack growth speed on FRP's delamination resistance.

\section{Empirical Verification of the INF Test}

Based on the above analysis, a test program that includes INF and ENF tests was conducted to measure FRP's delamination resistance. This section summarizes the experimental conditions used and the results obtained.

\subsection{Experimental Details}

3.1.1. Materials. FRP used for the study had isophthalic polyester as the matrix and unidirectional weft glass fibre fabric of $9-\mathrm{oz} / \mathrm{yd}^{2}\left(305 \mathrm{~g} / \mathrm{m}^{2}\right)$ as the reinforcement, provided by Triple M Fiberglass and ZCL Composites in Edmonton, respectively. A wet hand-lay-up technique was used to fabricate flat FRP panels of $220 \times 220 \mathrm{~mm}^{2}$, with fibre lay-up of $\left[0_{10} / \mathrm{F} / 0_{10}\right]$ in which $\mathrm{F}$ represents an aluminium insert film of $25 \mu \mathrm{m}$ thick, acting as a starting defect for the delamination growth. The use of aluminum film was to follow the practice in our previous work [12] so that, if needed, the test results can be compared with those obtained previously. The film used here was $42 \mathrm{~mm}$ long for the INF test and $50 \mathrm{~mm}$ for the ENF test to generate a starting defect of $25 \mathrm{~mm}$ within the span length. The film was coated with a Teflon-based mold release agent before the lay-up process, to avoid adhesion between the film and polyester resin. Preliminary tests confirmed that the film did not stick to the polyester resin. Therefore, no precrack was generated from the film tip and the film was left in the specimen for the delamination test. Stitching threads that held the fibre bundles together were removed in the middle 4 layers, that is, from the 9th to 12th layers, to reduce mechanical interlocking between the fracture surfaces during the delamination growth. These FRP panels were cured at room temperature for 24 hours and then postcured at $70^{\circ} \mathrm{C}$ for 20 hours to accelerate and complete the resin curing, resulting in a nominal thickness of $6.2 \mathrm{~mm}$ and fibre volume fraction of $38 \%$. Strip specimens with nominal width of $20 \mathrm{~mm}$ were then machined from the FRP panels for the testing, with 0degree fibre aligned in the longitudinal direction.

3.1.2. Delamination Test Setup and Procedure. Both INF and ENF tests were conducted using an INSTRON Universal Testing Machine. INF tests were conducted using a crosshead speed $(\dot{\delta})$ of $0.254 \mathrm{~mm} / \mathrm{min}(0.01 \mathrm{in} / \mathrm{min})$ and ENF tests $1.27 \mathrm{~mm} / \mathrm{min}$. Both types of tests had specimens loaded under 3-point bending. The half span length for the INF tests was $30 \mathrm{~mm}$ and that for the ENF tests $50 \mathrm{~mm}$. The load was recorded using a load-cell attached to the central loading pin, and the displacement was determined based on the crosshead speed and the loading time. Both loading and supporting pins had diameter of $5.16 \mathrm{~mm}$. Values of $a_{1}$ and $a_{2}$ in Figure 2 were chosen to be 30 and $12 \mathrm{~mm}$, respectively, which based on (8) allowed delamination growth for a distance of $40 \mathrm{~mm}$ in the $a_{1}$ direction before any delamination growth could occur in the $a_{2}$ direction. This delamination growth length is comparable to the crack growth length provided in other mode II delamination tests to establish the $R$-curve [13] thus deemed sufficient.

Taking the advantage of the translucent appearance of the FRP specimen, crack propagation was recorded using a digital camera (Nikon D70) at a sampling rate of $0.2 \mathrm{~Hz}$, that is, 1 picture for every 5 seconds, as shown in Figure 4. A paper strip with $1 \mathrm{~mm}$ marks was attached to the specimen edge so the crack growth length could be read directly from the photographs. For opaque FRPs, such as graphite/epoxy composites, location of the crack tip is not as obvious as 


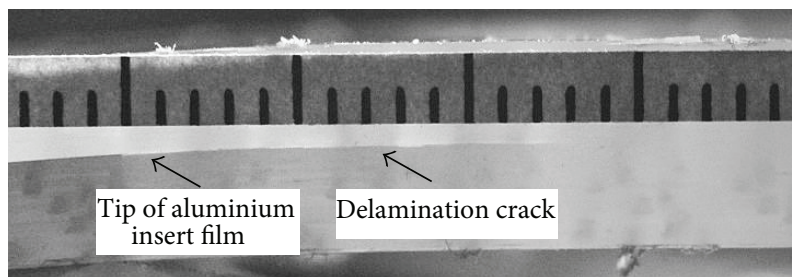

FIgURE 4: Photograph of an INF specimen, taken during the test.

that of the glass-fibre/polyester specimen. Thus, the crack length measurement by different observers may have various degrees of accuracy [14]. To improve the accuracy of measurement, some researchers [15] have suggested using liquid white painted along the specimen edge and others [16] used ultrasonic scan. Based on the recent work by Vinciquerra and Davidson [14] pretest compliance calibration can provide adequate accuracy and reliability. Therefore, a modified version of pretest compliance calibration method may be applicable to the crack length measurement for the INF test but is yet to be developed and verified.

For the ENF tests, $G_{\text {IIC }}^{\mathrm{ENF}}$ values were determined based on (1) using data at the maximum load, at which any unstable delamination growth was about to occur. $G_{\text {IIC }}^{\mathrm{ENF}}$ values for the initial nonlinear point or the intersection point with a straight line of 5\% compliance offset were not measured, as the loaddisplacement curve did not show any change of the slope until it reaches the maximum load.

\subsection{Results and Discussion}

3.2.1. INF Test. A typical load-displacement curve from the INF test and the corresponding change of crack growth are presented in Figure 5(a), and all load-displacement curves from 5 INF tests conducted in the study are summarized in Figure 5(b). For Figure 5(a), a tiny delamination crack was initiated at the far end of the insert film from the loading point, with the length of $a_{1}$ of Figure 2, at displacement of about $1.25 \mathrm{~mm}$, which is equivalent to a loading level of about 2000 N. Delamination growth at this stage was found to be very slow and its occurrence barely changed the slope of the load-displacement curve. The crack growth speed increased significantly when the curve reached a peak point, point A in Figure 5(a), corresponding to the displacement of $1.7 \mathrm{~mm}$. The fast delamination growth lasted for about $0.2 \mathrm{~mm}$ of the crosshead displacement, as marked by two dash lines in Figure 5(a). Further increase of the crosshead displacement resulted in a reduced delamination growth speed that remained relatively constant till the end of the test, with total delamination growth length of around $30 \mathrm{~mm}$. It should be noted that all 5 specimens showed stable delamination growth that occurred in the $a_{1}$ direction only, and the loaddisplacement curves were very reproducible except at around the peak load where relatively fast delamination growth occurred.

After the INF test, the two halves of the delaminated section were found to stick together by bridging fibres, as

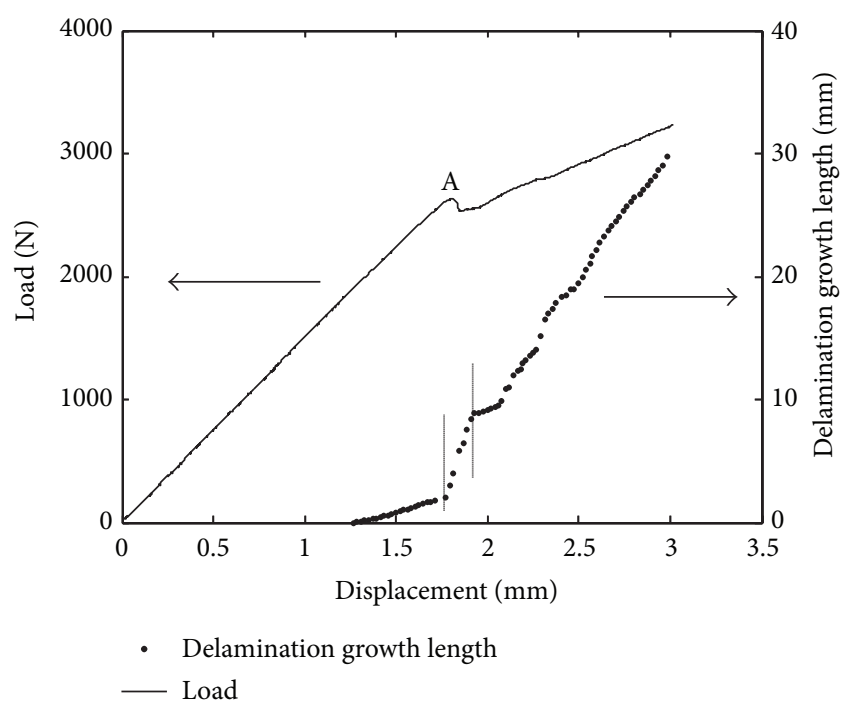

(a)

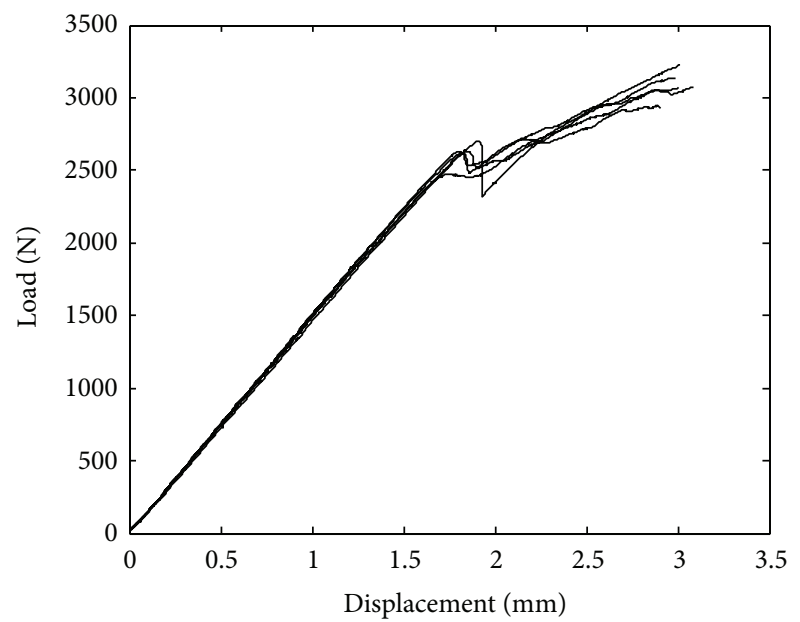

(b)

Figure 5: INF test results: (a) typical experimental data and (b) summary of 5 tests conducted in the study to show repeatability of the results.

shown in Figure 6 that was taken by slightly wedge-opening the specimen after the test. It should be noted that there were no signs of crack opening in tension during the test. We believe that the bridging fibres were initiated from the very beginning of the delamination growth and that their existence compensated for the loss of the bending stiffness due to the crack growth in the initial stage of the delamination development, resulting in little change of the slope for the loaddisplacement curve. The eventual breakage of the bridging fibres reduced the load-carrying capacity of the specimen and increased the delamination growth rate, such as that shown in Figure 5(a) where the crosshead displacement increased from 1.7 to $1.9 \mathrm{~mm}$. Further delamination growth, that is, after about $10 \mathrm{~mm}$ of crack development in Figure 5(a), slowed down again to a relatively constant speed that was believed to be the result of a combined effect of new surface formation 


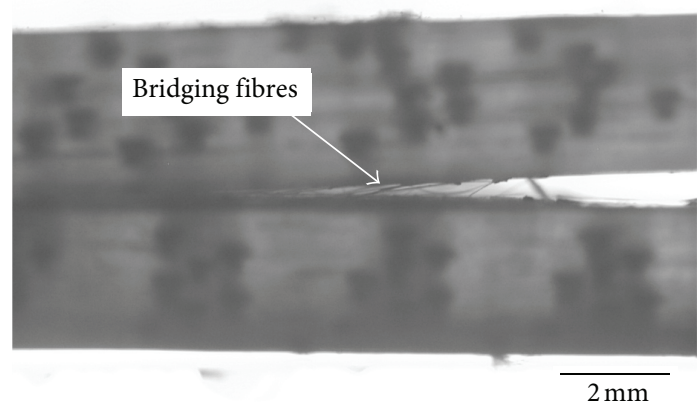

Figure 6: Photograph of a posttested INF specimen, showing bridging fibres between the fracture surfaces.

and breakage of bridging fibres. The final crack growth speed was between the crack growth speeds in the first two stages.

3.2.2. R-Curves. Compliance fitting method was used to establish $R$-curves from each INF test. The method is based on linear elasticity, using (5) to determine the energy release rate. The expression of $G$ given by (5) and (6) suggests that the compliance $C$ may be expressed as a linear function of $\left(a_{1}+a_{2}\right)^{-1}$. Therefore, linear curve fitting was applied to the plot of $C$ versus $\left(a_{1}+a_{2}\right)^{-1}$, as shown in Figure $7(\mathrm{a})$, and the corresponding $R$-curves for all specimens in Figure 7(b). It should be noted that only data after the fast delamination growth were used to determine the curve-fitting function of $C$ versus $\left(a_{1}+a_{2}\right)^{-1}$. As a result, the $R$-curves do not include the energy release rate during the initial stage of the delamination growth. Figure 7(b) indicates that the delamination resistance decreases slightly with the increase of the delamination crack length, and that some scattering exists among the curves, possibly due to the variation of the amount of bridging fibres in the specimens. The ENF specimens, on the other hand, did not show any noticeable amount of bridging fibres to affect the delamination growth.

3.2.3. Comparison of INF and ENF Test Results. The range of $G_{\text {IIC }}^{\mathrm{ENF}}$ values determined from the maximum load is also included in Figure 7(b), marked by a horizontal shaded band. The average $G_{\text {IIC }}^{\mathrm{ENF}}$ value is $1584 \mathrm{~J} / \mathrm{m}^{2}$ with a standard deviation of $85 \mathrm{~J} / \mathrm{m}^{2}$, which is slightly lower than the first value of the $R$ curves in Figure $7(\mathrm{~b})$. Since the $R$-curves are for delamination growth beyond the initial load drop, the $G_{\text {IIC }}$ value for the onset of delamination in the INF test was determined using (6) at the load $P$ where the initial slow delamination growth commenced, which is around $2000 \mathrm{~N}$ in Figure 5(a). Average $G_{\text {IIC }}$ determined in this way is $1532 \mathrm{~J} / \mathrm{m}^{2}$ with a standard deviation of $81 \mathrm{~J} / \mathrm{m}^{2}$, which is very close to the average $G_{\mathrm{IIC}}^{\mathrm{ENF}}$ value.

It should be pointed out that, unlike the ENF test, the INF test generated delamination growth outside the span section. Therefore, the delamination growth in the INF specimen

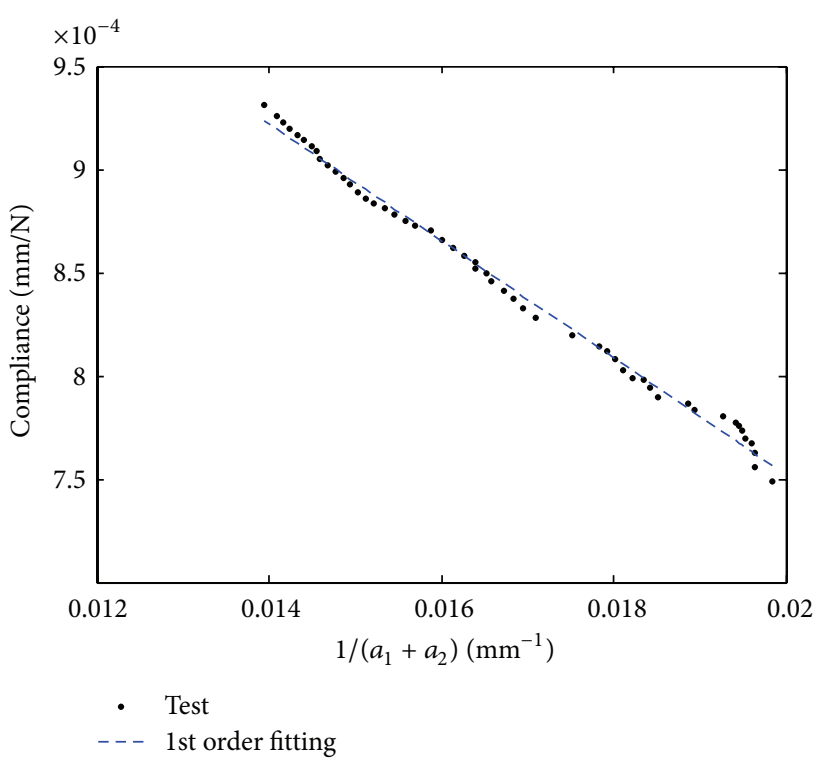

(a)

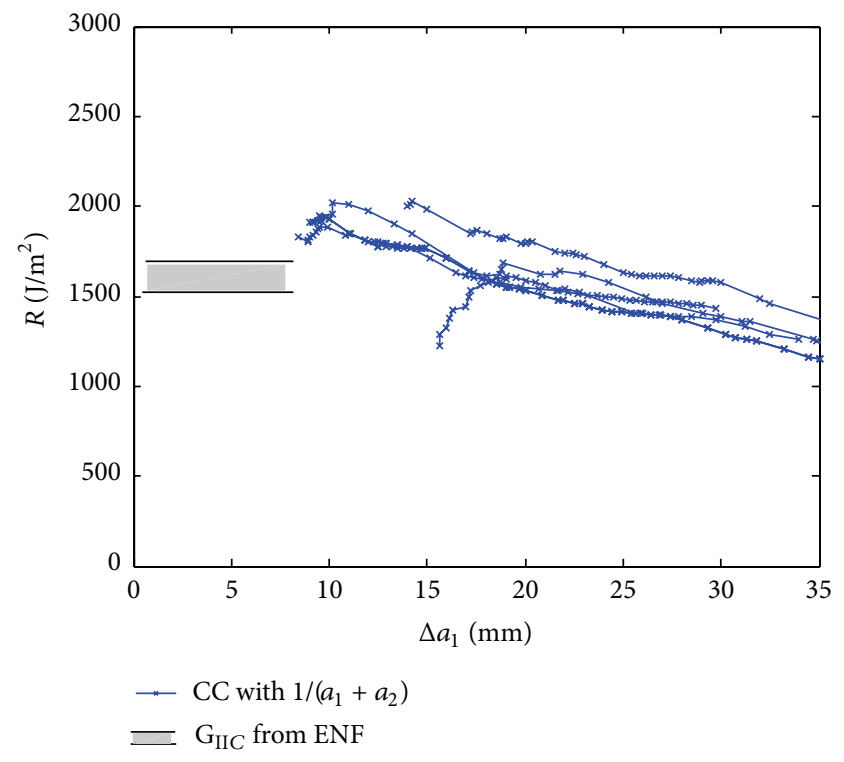

(b)

FIGURE 7: Compliance fitting method: (a) linear curve fitting of the compliance and (b) $R$-curves for all specimens.

was not subject to any transverse loading or bending, thus minimising their effects on the measured $G_{C}$ values.

\section{Conclusions}

A new test method, named INF test, is proposed to quantify mode II delamination toughness of fibre-reinforced polymers. The test generates very stable delamination growth. For glass-fibre-reinforced isophthalic polyester, the $R$-curves show a slightly downward trend with the delamination growth. The $G_{\text {IIC }}$ value for the onset of delamination was found to be very close to the $G_{\text {IIC }}$ value from the ENF test, determined from data at the maximum load. 
Unlike the ENF specimens, INF specimens were found to contain bridging fibres between fracture surfaces, probably due to the stable nature of crack growth. The bridging fibres are believed to be the result of relatively weak interfacial bonding between fibre and matrix, which must have caused delamination growth path deviating from the interlaminar region. Further study to elucidate the delamination behaviour with the presence of bridging fibres will be conducted in the near future.

The analysis for the INF test shows that the delamination growth speed is directly proportional to the test crosshead speed. Therefore, the INF test can be used to evaluate the effect of the crack growth speed on the delamination resistance. Since the insert film in the INF specimens may be placed in different interlaminar regions or between layers of different fibre orientation, the test may be used to study the corresponding variation in delamination resistance. Feasibility of such studies is being investigated.

\section{Acknowledgments}

The work was sponsored by the Natural Sciences and Engineering Research Council of Canada (NSERC) and Intelligent Sensing for Innovative Structures (ISIS Canada). The authors like to express their sincere appreciation to Dr. P. Davies in INFRMER, France, for providing generous and valuable comments about the paper. C. Fan also acknowledges the financial support from ASME Award and Izaak Walton Killam Memorial Scholarship during the course of the study. It should be noted that there is no relationship between the authors and INSTRON. They simply used the testing machine purchased from INSTRON for the study.

\section{References}

[1] A. A. Griffith, "The phenomena of rupture and flow in solids," Philosophical Transactions of the Royal Society A, vol. 221, no. 582-593, pp. 163-198, 1921.

[2] A. J. Russell and K. N. Street, "Moisture and temperature effects on the mixed-mode delamination fracture of unidirectional graphite/epoxy," in Delamination and Debonding of Materials, pp. 349-370, Pittsburgh, Pa, USA, 1985.

[3] K. Kageyama, M. Kikuchi, and N. Yanagisawa, "Stabilized end notched flexure test. Characterization of mode II interlaminar crack growth," in Proceedings of the 3rd Symposium on Composite Materials: Fatigue and Fracture, pp. 210-225, Philadelphia, $\mathrm{Pa}$, USA, November 1989.

[4] P. Davies, G. D. Sims, B. R. K. Blackman et al., "Comparison of test configurations for determination of mode II interlaminar fracture toughness results from international collaborative test programme," Plastics, Rubber and Composites Processing and Applications, vol. 28, no. 9, pp. 432-437, 1999.

[5] R. H. Martin and B. D. Davidson, "Mode II fracture toughness evaluation using four point bend, end notched flexure test," Plastics, Rubber and Composites Processing and Applications, vol. 28, no. 8, pp. 401-406, 1999.

[6] T. K. O’Brien, "Interlaminar fracture toughness: the long and winding road to standardization," Composites B, vol. 29, no. 1 , pp. 57-62, 1998.
[7] S. Hashemi, A. J. Kinloch, and J. G. Williams, "The effect of geometry, rate and temperature on the mode I, mode II and mixed-mode I/II interlaminar fracture of carbonfibre/poly(ether-ether-ketone) composites," Journal of Composite Materials, vol. 24, no. 9, pp. 918-956, 1990.

[8] H. Maikuma, J. W. Gillespie, and J. M. Whitney, "Analysis and experimental characterization of the center notch flexural test specimen for mode II interlaminar fracture," Journal of Composite Materials, vol. 23, no. 8, pp. 756-786, 1989.

[9] C. Fan, P.-Y. Ben Jar, and J. J. Roger Cheng, "Energy-based analyses of delamination development in fibre-reinforced polymers under 3-point bending," Composites Science and Technology, vol. 66, no. 13, pp. 2143-2155, 2006.

[10] B. D. Davidson, H. Hu, and R. A. Schapery, "Analytical cracktip element for layered elastic structures," Journal of Applied Mechanics, vol. 62, no. 2, pp. 294-305, 1995.

[11] Z. Yang, C. T. Sun, and J. Wang, "Fracture mode separation for delamination in platelike composite structures," AIAA Journal, vol. 38, no. 5, pp. 868-874, 2000.

[12] P.-Y. B. Jar, T. M. Dick, and T. Kuboki, "Comparison of testing methods for fibre-reinforced polymers (FRP) in resistance to in-plane sliding mode of delamination (Mode II)," Journal of Materials Science, vol. 40, no. 6, pp. 1481-1484, 2005.

[13] P. Davies, G. D. Sims, B. R. K. Blackman et al., "Comparison of test configurations for determination of mode II interlaminar fracture toughness results from international collaborative test programme," Plastics, Rubber and Composites Processing and Applications, vol. 28, no. 9, pp. 432-437, 1999.

[14] A. J. Vinciquerra and B. D. Davidson, "Effect of crack length measurement technique and data reduction procedures on the perceived toughness from four-point bend end-notched flexure tests," Journal of Reinforced Plastics and Composites, vol. 23, no. 10, pp. 1051-1062, 2004.

[15] E. Zile and V. Tamuzs, "Mode II delamination of a unidirectional carbon fiber/epoxy composite in four-point bend endnotched flexure tests," Mechanics of Composite Materials, vol. 41, no. 5, pp. 383-390, 2005.

[16] K. Kageyama, I. Kimpara, T. Suzuki, I. Ohsawa, M. Kanai, and Tsuno I, "Effects of test conditions on mode II interlaminar fracture toughness of four-point ENF specimens," in Proceedings of the 12th International Conference on Composite Materials (ICCM '99), Paris, France, 1999. 

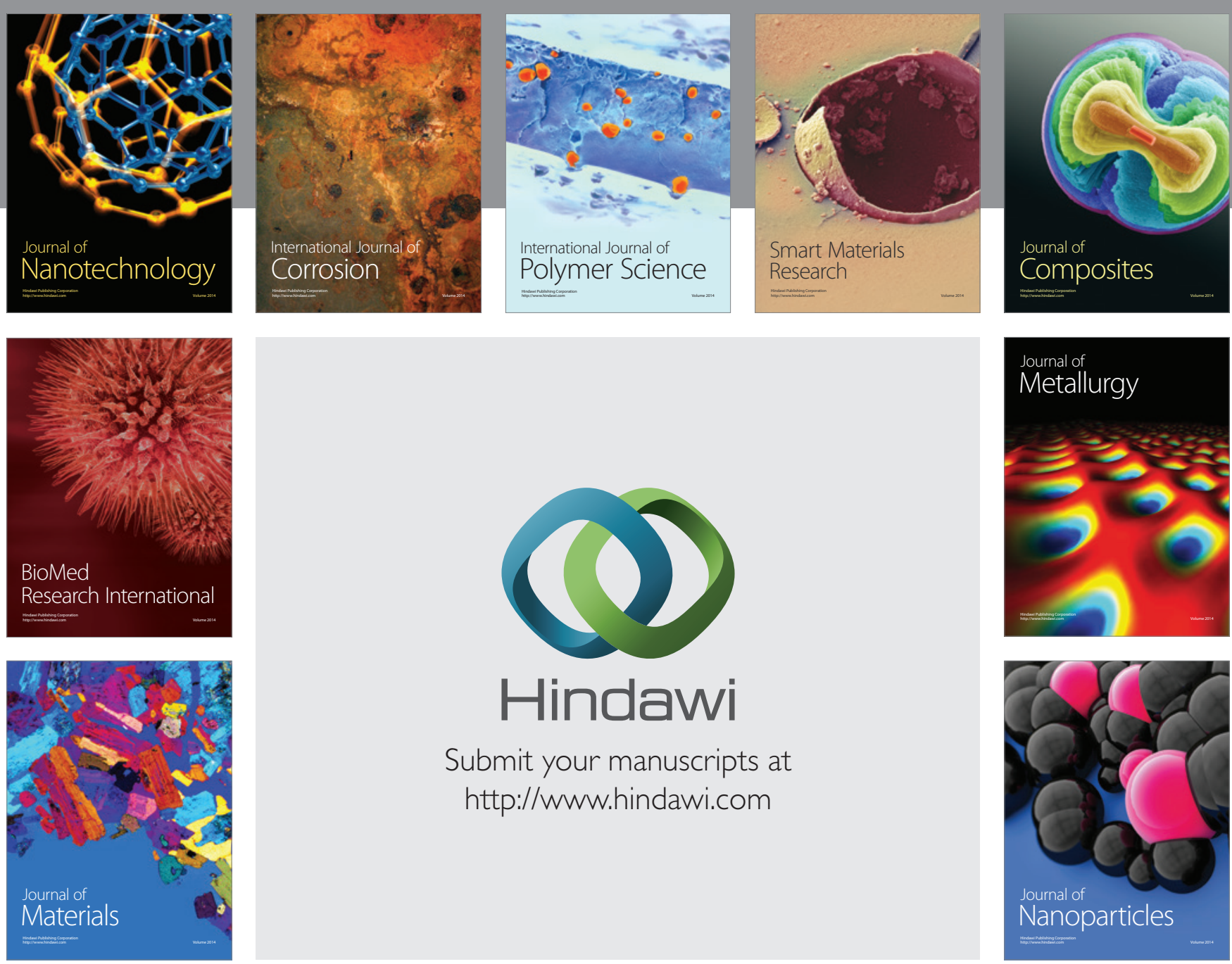

Submit your manuscripts at http://www.hindawi.com
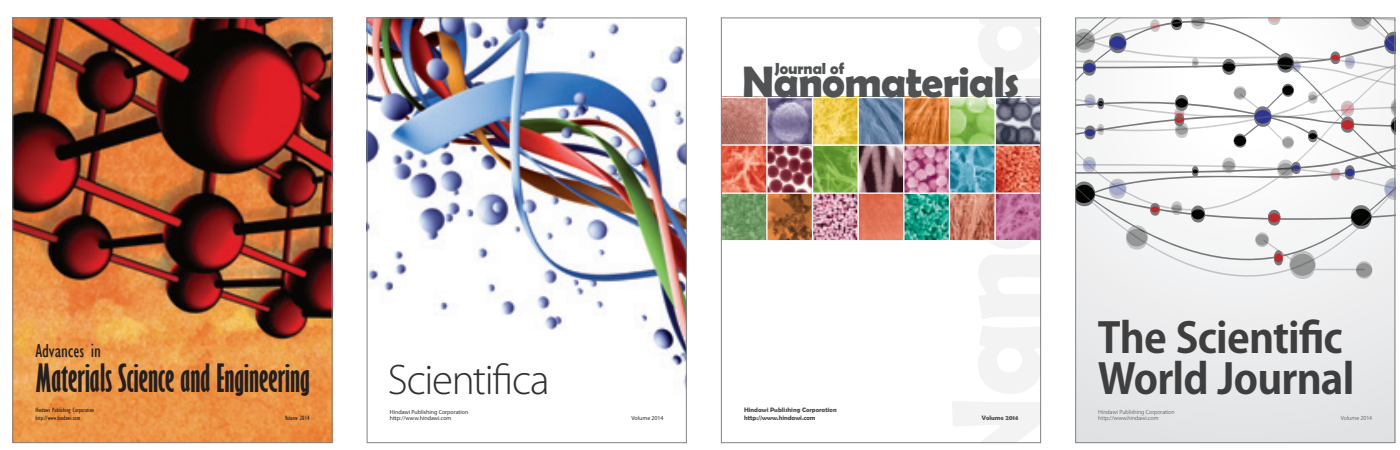

\section{The Scientific World Journal}
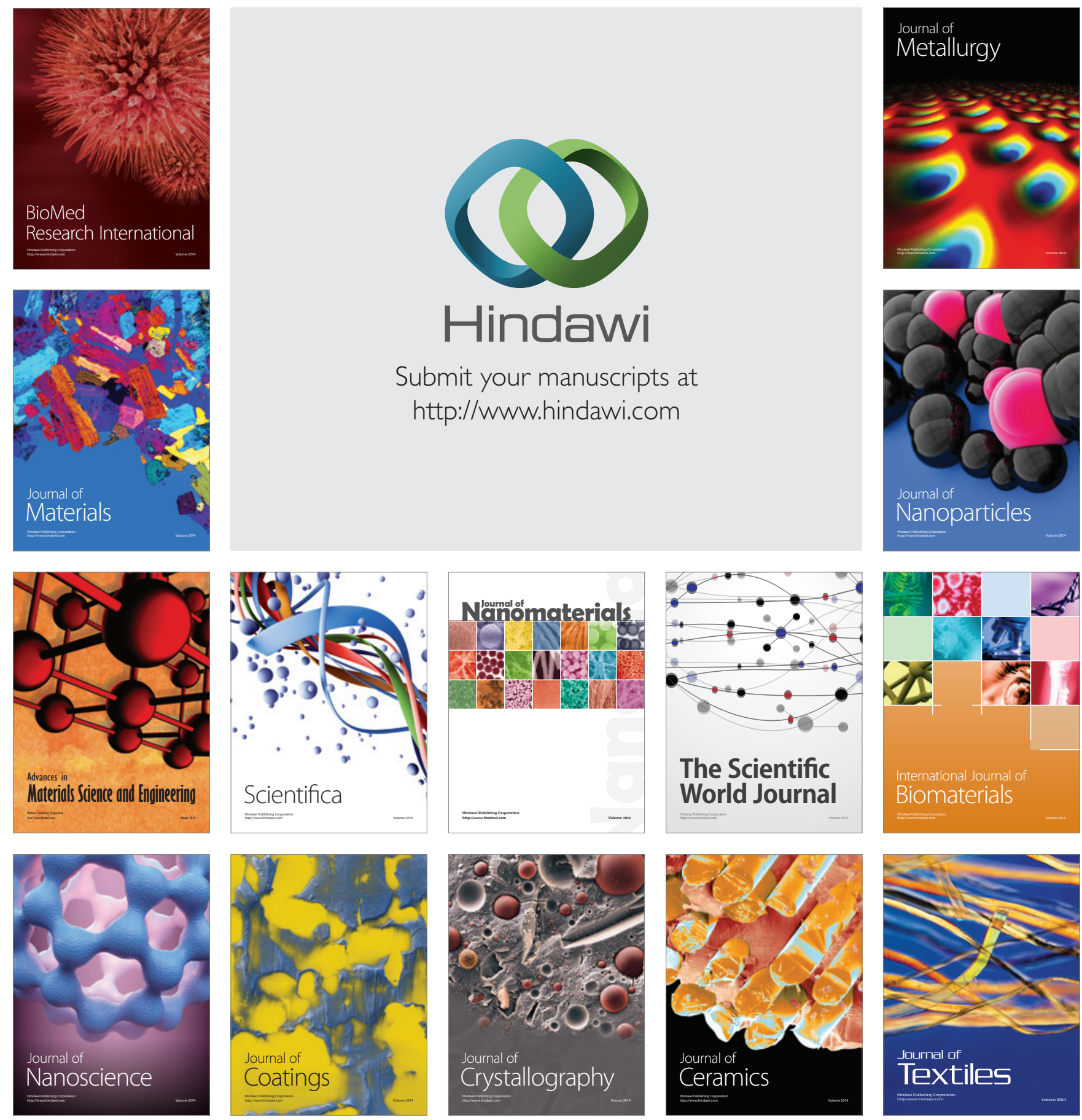